\title{
MONITORING THE DEPTH OF GENERAL ANAESTHESIA WITH BIS MONITOR IN THE COURSE OF SURGICAL PROCEDURE IN CHILDREN SHORTENS THE PERIOD OF RECOVERY FROM GENERAL ANAESTHESIA
}

\author{
Divak $\mathrm{J}^{1,2}$, Frelich $\mathbf{M}^{2}$, Dragula $\mathbf{M}^{1}$, Tomaskova H. ${ }^{3}$
}

\begin{abstract}
${ }^{1}$ Comenius University in Bratislava, Jessenius Faculty of Medicine in Martin and University Hospital, Department of Paediatric Surgery, Slovak Republic; ${ }^{2}$ Department of Anaesthesiology and Intensive Care Medicine, University Hospital Ostrava, Czech Republic; ' ${ }^{3}$ Centre of Epidemiological Research, Faculty of Medicine, University of Ostrava, Ostrava, Czech Republic
\end{abstract}

\begin{abstract}
Monitoring the depth of general anaesthesia (GA) enables the anaesthetist to reach the optimal depth of GA, and thus prevent the occurrence of too deep or too shallow anaesthesia, together with all associated consequences. Anaesthesia, which is too shallow, increases the risk of perioperative awareness. In adult patients, the incidence of perioperative awareness is $0.1-0.2 \%$ for the total number of GA procedures, in paediatric population, the clinical studies present the incidence of up to $5 \%$ (1973), $0.8 \%$ (2005) for the total number of GA procedures. Perioperative awareness is a serious complication, with possible psychological consequences for the patients, including post-traumatic stress disorder.

BIS monitoring is one of the possibilities how to assess the depth of GA. This technique is based on the assessment of EEG curve, when individual parameters of the EEG signal are, using mathematical methods, transformed into a dimensionless number, so-called bispectral index (BIS), the value of which is expressed on the scale from 0 to 100 , and which reflects the depth of general anaesthesia.

This prospective randomized clinical trial has proven, on a group of 101 children that the use of BIS monitor in the course of GA shortens the period of recovery from general anaesthesia, however, it does not decrease the consumption of inhalation anaesthetics when compared to GA performed without BIS monitoring. The results of the study confirmed the importance of monitoring the depth of GA in patients with intravenous administration of Propofol. The authors have observed an inverse linear relation between the values of BIS and MAC (minimum alveolar concentration).
\end{abstract}

Keywords: General anaesthesia, Perioperative awareness, Depth of general anaesthesia, Bispectral index

\section{INTRODUCTION}

The basic aim of general anaesthesia (GA), "the greatest gift for the art of medicine" (S. B. Nuland) (1), according to many definitions is to enable a painless performance of surgical or other painful invasive procedures. The management of GA should be aimed at reaching the optimal depth of GA, and also related rapid emergence of the patient from GA. With the current variable options of GA management (use of intravenous anaesthetics, strong analgesics, analgesics with a short effect and potent volatile anaesthetics, in combination with various methods of local anaesthesia), the importance of methods for measurement of the depth of GA increases. The depth of general anaesthesia is defined as a continuous progressive decrease of the CNS activity and decreased reactivity to stimuli. In the course of GA in adults, perioperative awareness is detected in $0.1-0.2 \%$ of patients (2). In the clinical practice, $95 \%$ of the cases of perioperative awareness are caused by a human error, or incorrect anaesthetic procedure, or possibly by a failure of the instru-

A d d r s s for corres pond e n c e:

Jan Divák, MD, Department of Anaesthesiology and Intensive Care Medicine, University Hospital Ostrava, Str. 17. listopadu N. 1790, 708 52, Ostrava-Poruba, Czech Republic

E-mail: dija@centrum.cz; Phone: +420 603858619 
ment, when, for example, the dose of anaesthetic is not supplied, or due to a failure of proper patient monitoring. Only in $2.5 \%$ of cases it is not possible to determine the cause (3). According to expert literature, there exists evidence showing that approximately $87 \%$ of cases of perioperative awareness may be accounted for insufficient depth of GA (4). However, only a limited amount of information is available in the modern paediatric anaesthesiology literature regarding perioperative awareness; the incidence of perioperative awareness in children is presented between $0.8 \%$ (2005) and $5 \%(1973)(5,6)$. Contrary to the adult population, laryngospasm presents a potentially significant complication of too shallow anaesthesia in children (7). Several studies have presented poor and indirect evidence about the BIS value being a poor and indirect predictor of complications in the course of placement and removal of the laryngeal mask $(8,9)$. Perioperative awareness may result in significant psychological complications in the post-operative period (e.g. posttraumatic stress disorder), and the patients may suffer from long-term and serious consequences $(10,11)$.

The depth of GA in our study was assessed using the BIS Vista monitor (Covidien), and was determined by the value of bispectral index (BIS). BIS is a dimensionless, numerical parameter, which is obtained from EEG data with continuous power spectral analysis and calculation of the degree of phasing among various frequencies of the EEG signal. The BIS value is a number between 0 (unconscious patient - isoelectric EEG curve) and 100 (fully awake patient) (12).

The main motto of the study was the presumption that one of the aims of anaesthetists is to prevent perioperative awareness, and thus the GA is managed rather towards "greater depth", which is associated with an increased consumption of anaesthetics, longer time of recovery from GA, and other side effects. The study had the following aims: to verify, whether the presence of GA depth monitoring using BIS monitor in children in the course of a surgical procedure leads to a shortening of the period of recovery from GA, and a lower consumption of the inhalation anaesthetic when compared with GA patients without monitoring the depth of anaesthesia.

\section{METHODS}

The study design was approved by the Local Ethics Committee of the University Hospital Ostrava. The study subjects enrolled in the study were paediatric patients from the $28^{\text {th }}$ day of age to 18 years of age, including, and classification ASA I. The BIS group is characterized with monitoring the depth of GA using the BIS monitor and management of the hypnotic component of GA towards BIS values between 40 and 60. The non-BIS group is characterized with management of the hypnotic component of GA according to minimal alveolar concentration (MAC), appropriate for the age of the child, without monitoring the depth of GA. Randomization was performed using the envelope method.

\section{Protocol of GA management}

Induction of GA was either inhalation: sevofluranum (Sevorane), with constant flows of gases $\mathrm{O}_{2}+\mathrm{AIR}$ in the ratio of $1: 1(2 \mathrm{l} / \mathrm{min})$, or intravenous: propofolum (Propofol 1\%) $(2-2.5$ $\mathrm{mg} / \mathrm{kg}$ iv.), furthermore analgesia using sufentanil citras (Sufenta) (0.1-0.3 ug/kg iv.), and relaxation, if needed: mivacurium chloride (Mivacron) (0.1-2 mg/kg iv.), or atracurii besilate (Tracrium) (0.3-0.6 mg/kg iv.). The maintenance stage of GA was standardly managed in the following way: hypnotic component of GA with titration of the dose of Sevoflurane, with the aim of achieving the value of BIS between 40-60 in the BIS group, or the aim of achieving the MAC value appropriate for the age of the child in the non-BIS group, with a defined flow of carrier mixture of gasses $\left(\mathrm{O}_{2}+\mathrm{AIR}\right.$, in the ratio of $1: 1$, with the flows of 0.5:0.5 1/min), and analgesia with Sufentanil (0.1-0.3 ug/kg iv.), and if needed relaxation with mivacurium (0.1 mg/kg iv.) or atracurium (0.1-0.2 mg/kg iv.). 


\section{Statistics}

Description statistics was used for the basic description of the patient file (median, arithmetic mean, standard deviation, frequency tables with absolute and relative counts). In order to evaluate the differences between the BIS and non-BIS groups, chi-square test was used for the qualitative markers. In order to analyse quantitative data, Shapiro-Wilk test of normality was used, and, based upon this test, non-parametric Mann-Whitney test was performed. Box plots were used for graphic representation. In order to analyse the relation between MAC and BIS, correlation and linear regression were applied. All statistical tests were assessed at the level of significance of $5 \%$. The results were processed using the Stata software, version 13.

\section{RESULTS}

The BIS group consisted of 51 patients, the non-BIS group of 50 patients. The patients were divided into three age groups: 0-1 year, 2-6 years, and 7-18 years. The largest number of patients was in the middle age group - children between one year and six years of age represented $60 \%$ of the patient population. No statistically significant differences were observed between the BIS and non-BIS groups as far as age distribution is concerned $(p=0.932)$. Among all diagnoses due to which the children were undergoing surgical procedures, the surgical diagnoses of hernia (inguinalis, umbilicalis, scrotalis), hydrocela (56\% in total), and retentio testis (19\%) were the most common. No statistically significant difference in the representation of diagnoses was observed among the BIS and non-BIS groups ( $\mathrm{p}=0.410)$.

In order to assess the individual stages of GA, including the time interval required for emergence from GA, the following time points were recorded in the course of every anaesthesia: time T1 (min): start of the surgical procedure (SSP), time T2: moment, when zero

Table 1: Individual stages of GA and the total duration of GA in the BIS and non-BIS groups

\begin{tabular}{|c|c|c|c|c|c|c|c|c|}
\hline $\begin{array}{l}\text { Stage of } \\
\text { GA (min) }\end{array}$ & Group & Number & Median & Mean & SD & Min. & Max. & p-value* \\
\hline \multirow{2}{*}{$\begin{array}{l}\text { Stage } \\
\text { (T1) }\end{array}$} & BIS & 51 & 10 & 10.3 & 3.75 & 4 & 20 & \multirow{2}{*}{0.0671} \\
\hline & non-BIS & 50 & 11 & 11.9 & 4.47 & 5 & 30 & \\
\hline \multirow{2}{*}{$\begin{array}{l}\text { Stage } 2 \\
\text { (T2-T1) }\end{array}$} & BIS & 51 & 16 & 28.3 & 27.60 & 5 & 138 & \multirow{2}{*}{0.3395} \\
\hline & non-BIS & 50 & 20 & 30.1 & 29.71 & 7 & 170 & \\
\hline \multirow{2}{*}{$\begin{array}{l}\text { Stage } 3 \\
\text { (T3-T2) }\end{array}$} & BIS & 51 & 4 & 3.9 & 1.89 & 1 & 10 & \multirow{2}{*}{0.4089} \\
\hline & non-BIS & 50 & 3 & 4.0 & 2.99 & 1 & 15 & \\
\hline \multirow{2}{*}{$\begin{array}{l}\text { Stage } 4 \\
\text { (T4-T3) }\end{array}$} & BIS & 51 & 3 & 4.1 & 3.46 & 1 & 17 & \multirow{2}{*}{0.0017} \\
\hline & non-BIS & 50 & 5 & 5.1 & 2.22 & 1 & 10 & \\
\hline \multirow{2}{*}{$\begin{array}{l}\text { Total } \\
\text { duration } \\
\text { of GA (T4) }\end{array}$} & BIS & 51 & 37 & 46.6 & 28.69 & 19 & 155 & \multirow{2}{*}{0.2876} \\
\hline & non-BIS & 50 & 40 & 51.0 & 34.34 & 20 & 210 & \\
\hline
\end{tabular}

* Mann-Whitney test; (T1 (min): start of the surgical procedure (SSP), T2 (min): moment, when zero concentration of inhalation anaesthetic was set on the vaporizer, T3(min): end of surgical procedure (ESP), T4(min): removal of the device securing breathing passageways) 
concentration of inhalation anaesthetic was set on the vaporizer, time T3: end of surgical procedure (ESP), and time T4: removal of the device securing breathing passageways (laryngeal mask, intubation cannula); based upon the differences in these times, the length of individual stages of GA was determined, GA: stage $1=\mathrm{T} 1$, stage 2 : T2-T1, stage $3=\mathrm{T} 3-\mathrm{T} 2$, stage $4=$ T4-T3.

Table 1 shows the individual time intervals: stage 1 , stage 2 , stage 3 , stage 4 , and the total duration of GA. From the data in the table it is clear that the times in the BIS group were mostly shorter when compared to the non-BIS group, however, statistical difference was observed only in stage 4, when the time in the BIS group in this stage was significantly shorter than in the non-BIS group ( $p=0.0017)$.

When assessing the difference of T4-T2 times, no statistically significant difference of middle values between the BIS and non-BIS group was observed ( $p=0.063$ ), although the values in the BIS group were lower (Table 2, Figure 1); nevertheless, as clearly apparent from Figure 1, outliers were present in the patient file (in both BIS and non-BIS groups). These outliers represented "patients with complications after waking up", and these values may have distorted the results. For this reason, one more comparison was performed, with exclusion of these patients. After removal of these values from the patient file, we observed a statistically significant difference in the middle differentiation of T4-T2 times $(\mathrm{p}=0.017)$. This time period was shorter in the BIS group. From the total number of 101 patients, 6 patients were excluded due to them being outliers, the cause of which was a longer period of emergence from GA (4 patients in the BIS group, 2 patients in the non-BIS group).

Table 2: T4-T2 (min) (without outliers, with outliers)

\begin{tabular}{|l|l|c|c|c|c|c|c|c|}
\hline \multirow{2}{*}{ Patient file } & \multirow{2}{*}{ Group } & \multicolumn{6}{|c|}{ T4-T2 (min) } & \multirow{2}{*}{ p-value* } \\
\cline { 3 - 9 } & Number & Median & $\begin{array}{c}\text { Arithm } \\
\text { etical } \\
\text { mean }\end{array}$ & SD & Min. & Max. & \\
\hline Total file & BIS & 51 & 7.0 & 8.1 & 3.68 & 3.0 & 21.0 & \multirow{2}{*}{0.0634} \\
\hline \multirow{2}{*}{$\begin{array}{l}\text { Excluding the } \\
\text { patients with } \\
\text { complications }\end{array}$} & non-BIS & 50 & 9.0 & 9.1 & 3.73 & 4.0 & 23.0 & \\
\cline { 2 - 8 } & BIS & 47 & 7.0 & 7.3 & 2.36 & 3.0 & 13.0 & \multirow{2}{*}{0.0172} \\
\cline { 2 - 8 } & non-BIS & 48 & 9.0 & 8.6 & 2.76 & 4.0 & 14.0 & \\
\hline
\end{tabular}

* Mann-Whitney test

Statistically significant difference was observed in the length of stage 4 (T4-T3) ( $p=0.0017$ ) (Table 1), which also characterizes the period of emergence from GA. The average value (mean $\pm \mathrm{SD}$ ) was the following: BIS $4.1 \pm 3.46 \mathrm{~min} / \mathrm{non}-\mathrm{BIS} 5.1 \pm 2.22 \mathrm{~min}$.

For the induction of GA, inhalation induction was used in $77 \%$, intravenous induction in 23\%; no statistically significant difference was observed between the BIS and non-BIS groups $(\mathrm{p}=0.444)$.

In order to determine the consumption of the inhalation anaesthetic with MAC, we utilized the fact that in order to reach a higher MAC value, greater amount of the inhalation anaesthetic is required (under conditions of constant flow of gasses). To be able to determine the consumption of the inhalation anaesthetic, GA was divided into three consecutive stages: stage A: from the start of anaesthesia until the SSP moment, stage B: from SSP until the moment, when zero concentration of inhalation anaesthetic was set on the vaporizer, and stage $C$ : from the moment of shutting-off the inhalation anaesthetic until the moment of removing the device for securing breathing passageways. 
Table 3: MAC and BIS values in the course of GA: stages A, B, C

\begin{tabular}{|c|c|c|c|c|c|c|c|c|c|c|}
\hline & & \multicolumn{6}{|c|}{ MAC } & \multicolumn{2}{|c|}{ BIS } & \\
\hline \multirow{2}{*}{ Stage } & \multirow[b]{2}{*}{ Group } & \multicolumn{3}{|c|}{ Inhalation induction } & \multicolumn{3}{|c|}{ Intravenous induction } & \multirow[b]{2}{*}{$\begin{array}{l}\text { Inhalation } \\
\text { induction }\end{array}$} & \multirow[b]{2}{*}{$\begin{array}{c}\text { Intravenous } \\
\text { induction }\end{array}$} & \multirow[b]{2}{*}{ p-value* } \\
\hline & & BIS & non-BIS & p-value* & BIS & $\begin{array}{l}\text { non- } \\
\text { BIS }\end{array}$ & $\mathrm{p}$-value* & & & \\
\hline \multirow{6}{*}{ A } & Number & 79 & 83 & \multirow{6}{*}{0.8654} & 7 & 8 & \multirow{6}{*}{0.2446} & 69 & 34 & \multirow{6}{*}{0.026} \\
\hline & Median & 2.20 & 2.20 & & 1.10 & 0.55 & & 46 & 68 & \\
\hline & Mean & 2.25 & 2.26 & & 1.24 & 0.73 & & 46.9 & 64.1 & \\
\hline & $\mathrm{SD}$ & 0.654 & 0.704 & & 0.714 & 0.413 & & 18.04 & 30.58 & \\
\hline & Min. & 1.0 & 0.9 & & 0.2 & 0.3 & & 15 & 17 & \\
\hline & Max. & 3.7 & 3.9 & & 2.4 & 1.3 & & 96 & 97 & \\
\hline \multirow{6}{*}{ B } & Number & 125 & 167 & \multirow{6}{*}{0.0377} & 61 & 85 & \multirow{6}{*}{0.0043} & 120 & 61 & \multirow{6}{*}{$<0.001$} \\
\hline & Median & 1.50 & 1.50 & & 1.10 & 1.20 & & 50 & 40 & \\
\hline & Mean & 1.60 & 1.48 & & 1.23 & 1.28 & & 49.9 & 35.3 & \\
\hline & $\mathrm{SD}$ & 0.403 & 0.288 & & 0.468 & 0.265 & & 10.05 & 12.54 & \\
\hline & Min. & 0.9 & 0.7 & & 0.4 & 0.4 & & 27 & 5 & \\
\hline & Max. & 2.6 & 2.3 & & 2.9 & 1.9 & & 73 & 58 & \\
\hline \multirow{6}{*}{$\mathrm{C}$} & Number & 124 & 108 & \multirow{6}{*}{0.5133} & 37 & 44 & \multirow{6}{*}{0.0547} & 124 & 36 & \multirow{6}{*}{0.046} \\
\hline & Median & 0.50 & 0.60 & & 0.50 & 0.60 & & 63.5 & 61 & \\
\hline & Mean & 0.73 & 0.73 & & 0.57 & 0.70 & & 60.6 & 55.0 & \\
\hline & $\mathrm{SD}$ & 0.503 & 0.420 & & 0.393 & 0.369 & & 10.36 & 14.85 & \\
\hline & Min. & 0.2 & 0.2 & & 0.1 & 0.2 & & 33 & 13 & \\
\hline & Max. & 2.4 & 1.7 & & 2.1 & 1.4 & & 77 & 73 & \\
\hline
\end{tabular}

* Mann-Whitney test; (Stage A (min): from the start of anaesthesia until T1 (SSP), stage B (min): from $\mathrm{T} 1$ to $\mathrm{T} 2$, stage $\mathrm{C}$ (min): from $\mathrm{T} 2$ to $\mathrm{T} 4$ )

Table 4: BIS and MAC values at time T4 (time of removal of the device for securing breathing passageways)

\begin{tabular}{|l|c|c|c|c|c|c|c|}
\hline Group & Parameter & Number & Median & Arithmetical mean & SD & Min. & Max. \\
\hline \multirow{2}{*}{ BIS } & MAC4 & 51 & 0.3 & 0.31 & 0.09 & 0.1 & 0.4 \\
\cline { 2 - 8 } & BIS4 & 50 & 68.0 & 68.6 & 3.88 & 60.0 & 77.0 \\
\hline non-BIS & MAC4 & 50 & 0.3 & 0.34 & 0.09 & 0.2 & 0.6 \\
\hline
\end{tabular}


In this study, MAC and BIS values were determined in time T4, i.e. the time of removal of the device for securing breathing passageways. The MAC and BIS values did not differ significantly at this time $(\mathrm{p}=0.0971)$.

While examining the relation between MAC and BIS, when both of these quantities determine the depth of GA, using the statistical data obtained in the course of the study, MAC and BIS values were placed collectively (stages A, B, C) into two charts (according to the induction of GA: inhalation, intravenous); subsequently, the following two charts were modelled:

$>$ Group of patients with inhalation induction of anaesthesia (Group 1): (correlation coefficient: $r=-0.57) \mathrm{BIS}=66.2-9.80 \mathrm{MAC}$

$>$ Group of patients with intravenous induction (Group 2): (correlation coefficient: $r=$ $-0.65) \mathrm{BIS}=61.3-18.83 \mathrm{MAC}$

From Fig. 1, as well as the regression coefficients it is apparent, that the curve is steeper in Group 2, which means that with identical BIS values in Group 2, the MAC value is lower than in Group 1.

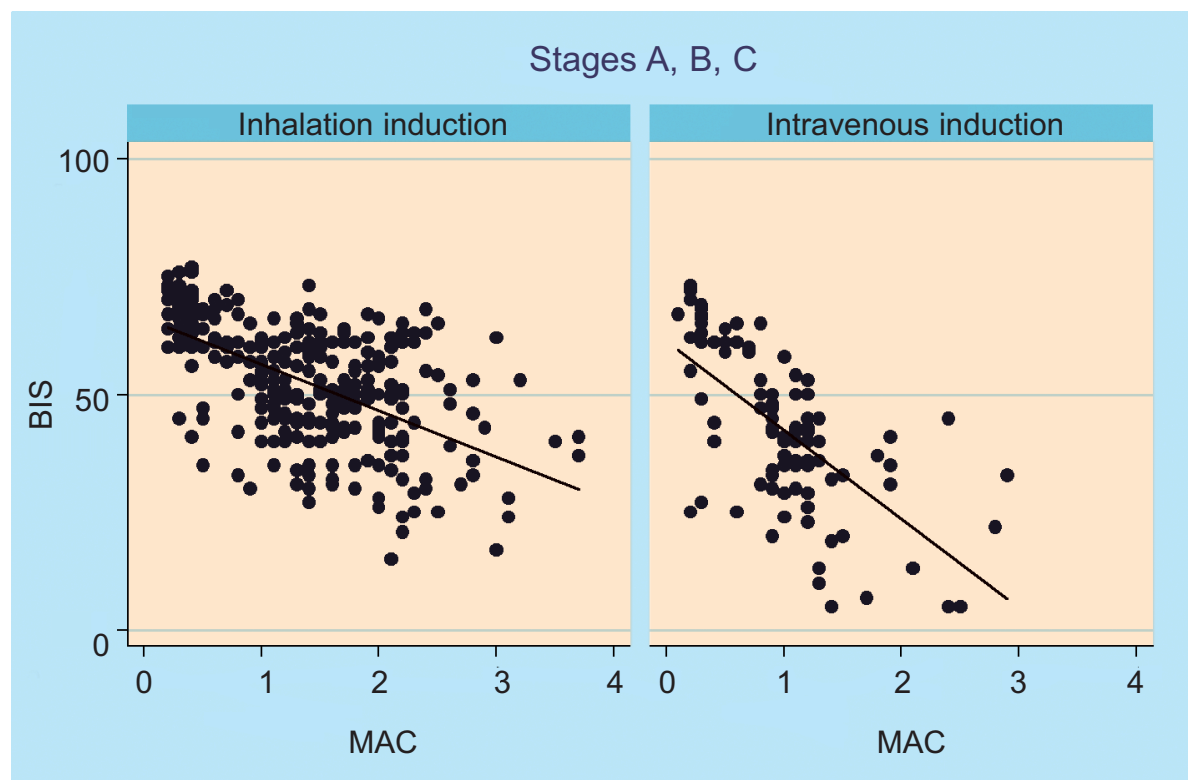

Fig. 1: Relation between MAC and BIS (stages A, B, C): inhalation induction, intravenous induction

\section{DISCUSSION}

In order to compare the time of emergence from GA in the BIS and non-BIS groups, two time intervals were defined. The first interval: from the moment when zero concentration of inhalation anaesthetic was set on the vaporizer (time T2) until the moment of removal of the device for securing breathing passageways (time T4). The second interval: from the time of the end of the surgical procedure (time T3) until the moment of removal of the device for securing breathing passageways (time T4). The following values were observed in the BIS and non-BIS groups: interval T4-T2 (min): BIS group: $8.1 \pm 3.68 \mathrm{~min} /$ non-BIS group 9.1 $\pm 3.73 \mathrm{~min}$; the period in the BIS group is shorter, however, the difference is not statistically significant $(\mathrm{p}=0.0634)$. After excluding the outliers due to significantly longer period 
of emergence from GA (BIS group: 4 patients, non-BIS group: 2 patients), the differences became statistically significant: interval T4-T2 (min): BIS group: $7.3 \pm 2.36 \mathrm{~min}$, non-BIS group: $8.6 \pm 2.76 \mathrm{~min}(\mathrm{p}=0.0172)$. Interval T4-T3 $(\mathrm{min})$ is already statistically significant; BIS group: $4.1 \pm 3.46 \mathrm{~min}$, non-BIS group: $5.1 \pm 2.22 \mathrm{~min}(\mathrm{p}=0.0017)$. Based upon the above-presented results, it is possible to conclude that GA management with monitoring the depth of GA decreases the time of emergence from GA. The T4-T3 interval in our study (BIS group: $4.1 \pm 3.46 \mathrm{~min} /$ non-BIS group: $5.1 \pm 2.22 \mathrm{~min}$ ) correlates with the interval observed in the study of Panchal (13), which presents identical time interval (recovery time), corresponding with the T4-T3 interval in our study: $5.75 \pm 1.07 \mathrm{~min}$; this time is shorter both in the BIS and non-BIS groups. It is also possible to find several other studies in the literature, which present a shorter time of emergence from GA in older children, in relation to the presence of BIS monitoring in the course of GA; the results of our study also support these observations $(14,15,16)$.

In order to determine the consumption of inhalation anaesthetic in individual stages of GA, we used the MAC value. We based our procedure on the presumption that the depth of GA will be monitored more precisely and more exactly in the BIS group when compared to the non-BIS group. We evaluated the group with inhalation induction and the group with intravenous induction separately. In the group of patients with inhalation induction in the initial stage of GA, i.e. from the induction until the start of the surgical procedure, the following values were observed: MAC: BIS groups: $2.25 \pm 0.654$ / non-BIS group: $2.26 \pm 0.704$; the values did not differ in the maintenance stage of GA: BIS group: $1.60 \pm 0.403$ / non-BIS group: $1.48 \pm 0.288$ and in the last stage of GA (from the moment of shutting-off the inflow of inhalation anaesthetic until the moment of removing the device for securing breathing passageways): BIS group: $0.73 \pm 0.503$ / non-BIS group: $0.73 \pm 0.420$. In the group of patients with the intravenous induction, in which the number of patients was significantly lower, we obtained the following MAC values: induction of GA: BIS group: $1.24 \pm 0.714$ / non-BIS group: $0.73 \pm 0.413$, maintenance stage of GA: BIS group: $1.23 \pm 0.468$ / non-BIS group: $1.28 \pm 0.265$, and the last stage of GA (from shutting off the inflow of inhalation anaesthetic until removing the device for securing breathing passageways): BIS group: $0.57 \pm 0.393$ / non-BIS group: $0.70 \pm 0.369$ (Table 3). In the group of patients with inhalation induction, in three consecutive stages of GA, in both BIS and non-BIS groups, no different MAC values were observed. In the group of patients with intravenous induction, we observed differences in MAC values, mainly in the induction stage of GA, when the MAC values were higher in the BIS group than in the non-BIS group. It is possible to assume that in case of intravenous induction of GA, without monitoring the depth of GA, there exists later onset of the inhalation anaesthetic, and thus exists a higher probability of perioperative awareness. This stage of GA following administration of intravenous anaesthetic, until the onset of inhalation anaesthetic is critical in the sense of incidence of perioperative awareness; the importance of monitoring the depth of GA in this situation is stressed also in expert literature (2). We did not observe any lower MAC value in the BIS group of patients, and we did not prove the fact that GA management using BIS monitor decreases the consumption of inhalation anaesthetic when compared to GA managed without BIS monitoring.

In adult patients, we observed that the use of BIS monitoring decreases the incidence of perioperative awareness in high-risk patients (17). Also several studies examining the use of BIS, Narcotrend index, and entropy have proven a decreased amount of the anaesthetic used, decreased incidence of perioperative awareness, and shortening of the period of emergence from GA. However, the observed improvements are mostly minor, and some of the analysed studies did not obtain any evidence about improvement of these outcomes (18). The practice of administration of anaesthesia in children widely differs, and there exist arguments for, as well as against the need of monitoring the depth of GA in children (7). The incidence of perioperative awareness in children is lower than in adult patients $(6,19)$. It has been proven that monitoring the depth of GA may prevent the occurrence of too-shallow anaesthesia, which means preventing the main complication of paediatric anaesthesia: 
laryngospasm. Furthermore, it has been proven that the BIS value is a poor predictor of complications during insertion and removal of devices for securing breathing passageways $(8,9)$. The study performed by Schwartz, with the patient group of 240 children, assessing the BIS monitoring in children in the course of maintenance stage of GA (20) showed a significant variability and surprisingly high values of BIS in a large proportion of paediatric patients; data obtained in the study suggest, that BIS monitor is not a reliable monitor of GA depth. On the contrary, the summary presented by Davidson shows that BIS monitoring is the most studied means of monitoring depth of GA, and although its use may find justification in older children, its use in new-borns cannot be recommended (7).

When assessing the interval of emergence from GA in the BIS and non-BIS groups, we observed MAC and BIS values in time T4, i.e. at the moment of removal of the device for securing breathing passageways. The observed MAC values did not differ in the BIS and non-BIS groups: BIS group: MAC $(0.31 \pm 0.09)$, and corresponding BIS $(68.6 \pm 3.88)$ / nonBIS group: MAC $(0.34 \pm 0.09)$ (Table 4$)$. When compared to the study performed by Panchal, with a similar design (13), which also presents MAC and BIS values corresponding with time T4: BIS $(75.4 \pm 5.97)$ and MAC $(0.07 \pm 0.16)$, the BIS values in our study are lower (and MAC values accordingly higher): MAC $(0.31 \pm 0.09)$, BIS $(68.6 \pm 3.88)$; nevertheless, in our study, we did not observe any post-operative complications at the recovery room among our study group of 101 patients, and the presented MAC and BIS values may be regarded as safe for removal of devices for securing breathing passageways.

When studying the relation of MAC and BIS values, based upon the data obtained in our study, we managed to identify an inverse linear dependency (Figure 1), in accordance with the results of studies performed by Panchal and Denman $(13,21)$. In case of intravenous administration of medicines, the curve is steeper, which means that identical BIS value corresponds with a lower MAC value; furthermore, the figure shows a higher variance of BIS values (towards the values below 40, as well as values above 60), which confirms and strengthens the importance of GA depth monitoring in the case of intravenous administration of medicines, in accordance with published literature.

\section{CONCLUSIONS}

The use of BIS monitoring in the course of GA in paediatric patients shortens the period of emergence from GA, and does not decrease the consumption of inhalation anaesthetic, when compared to GA without monitoring the depth of GA.

The use of BIS monitoring in the course of GA in children does not affect the value of MAC at the moment of removing the device for securing breathing passageways at the end of GA; the value of MAC remains identical, regardless whether BIS monitoring is present or not.

There exists an inverse linear dependency between the values of MAC and BIS.

The importance of monitoring the depth of GA with the BIS monitor is enhanced with the intravenous administration of anaesthetics (Propofol).

\section{REFERENCES}

1. Čumlivski R. Současné představy o působení anestezie - mají význam pro anesteziologieckou praxi. In: http://www.csarim.cz/Public/csim/CSARIM\%202014/2cumlivski.pdf

2. Sinha PK et al. Monitoring devices for measuring the depth of anaesthesia-An overview. Indian Journal of Anaesthesia 2007; 51(5): 365.

3. Hargrove RL. Awareness under anaesthesia. Journal of the Medical Defence Union 1987; 3(1): 9-11.

4. Shanks AM et al. Alerting thresholds for the prevention of intraoperative awareness with explicit recall: a secondary analysis of the Michigan Awareness Control Study. European Journal of Anaesthesiology 2015; 32 (5): 346-353. 
5. Borzova V, Smith C. Monitoring and prevention of awareness in trauma anesthesia. The Internet Journal of Anestshesiology 2010; 23, 2.

6. Davidson AJ et al. Awareness during anesthesia in children: a prospective cohort study. Anesthesia \&Analgesia 2005; 100 (3): 653-661.

7. Davidson A J. Monitoring the anaesthetic depth in children-an update. Current Opinion in Anesthesiology 2007; 20 (3): 236-243.

8. Lim SI, Chambers N A, Somerville NS. Can Bispectral Index aid laryngeal mask placement in children? Pediatric Anesthesia 2006; 16 (12): 1244 - 1250.

9. Sinha A, Sood J. Safe removal of LMA in children-at what BIS? Pediatric Anesthesia 2006; 16 (11): 1144-1147.

10. Lennmarken C, Bildfors K, Enlund G, Samuelsson P, Sandin R. Victims of awareness. Acta Anaesthesiol Scand 2002; 46, 229-31.

11. Sániová B, Drobný M. Consciousness and general anaesthesia: Recent View. Neuroendocrinol Lett 2008; 29(6): 822-083.

12. Ševčík P, Matějovič M (eds.). Intenzivní medicína. 3., přeprac. a rozš. vyd. Praha: Galén, c 2014. ISBN 978 80-7492-066-0.

13. Panchal NN, Swadia NP, Patel MG. Correlation of BIS Index with Sevoflurane Concentration in Paediatric Anaesthesia. National Journal of Medical Research 2014; 4 (2): 156-160.

14. Bannister $\mathrm{CF}$ et al. The effect of bispectral index monitoring on anesthetic use and recovery in children anesthetized with sevoflurane in nitrous oxide. Anesthesia \& Analgesia 2001; 92 (4): 877881.

15. Messieha ZS et al. Bispectral index system (BIS) monitoring reduces time to extubation and discharge in children requiring oral presedation and general anesthesia for outpatient dental rehabilitation. Pediatric dentistry 2005; 27 (6): 500-504.

16. Messieha Z S et al. Bispectral Index System (BIS) monitoring reduces time to discharge in children requiring intramuscular sedation and general anesthesia for outpatient dental rehabilitation. Pediatric dentistry 2004; 26 (3): 256-260.

17. Myles PS et al. Bispectral index monitoring to prevent awareness during anaesthesia: the B-Aware randomised controlled trial. The Lancet 2004; 363 (9423): 1757-1763.

18. Bruhn J et al. Depth of anaesthesia monitoring: what's available, what's validated and what's next?. British journal of anaesthesia 2006; 97 (1): 85-94.

19. Lopez $U$ et al. Incidence of awareness during general anaesthesia in children. British Journal of Anaestesia 2004; 93, 490P-491P.

20. Schwartz D et al. BIS in children during maintenance anesthesia. Rom Anest Terap Int 2011; 18, 95-100.

21. Denman WT et al. Pediatric evaluation of the bispectral index (BIS) monitor and correlation of BIS with end-tidal sevoflurane concentration in infants and children. Anesthesia \& Analgesia 2000; 90 (4): 872-877.

Received: April,24,2016

Accepted: July,17,2016 